\title{
Disparities of age-based cancer-specific survival improvement with various clinicopathologic characteristics for kidney cancer
}

This article was published in the following Dove Press journal: Cancer Management and Research

\author{
Kaitai Liu, ${ }^{1,2}$ \\ Ping Wang, ${ }^{3}$ \\ Xinli Zhu,' \\ Yanping Bei, ${ }^{2}$ \\ Zhen Zheng, ${ }^{2}$ \\ Senxiang Yan'
}

'Department of Radiation Oncology, the First Affiliated Hospital, Zhejiang University of Medicine, Hangzhou, China; ${ }^{2}$ Department of Radiation Oncology, Lihuili Hospital, Ningbo Medical Center, Ningbo, China; ${ }^{3}$ Zhejiang Provincial Key Laboratory of Pathophysiology, Ningbo University School of Medicine, Ningbo, China
Correspondence: Senxiang Yan Department of Radiation Oncology, The First Affiliated Hospital, Zhejiang University of Medicine, No. 79, Qing Chun Road, Hangzhou 310009, China Email yansenxiang2000@।63.com
Introduction: Whether or not age is a predictor of kidney cancer survival is currently unknown but debated. It is also unknown whether improved kidney cancer survival is associated with age with particular clinicopathologic characteristics. The aim of this study was to evaluate kidney cancer survival in four age-based subgroups of patients by analyzing the Surveillance, Epidemiology, and End Results-registered database.

Methods: Age-based survival disparity by sex, race, marital status, year of diagnosis, pathological grade, histological type, and stage was measured. The impact of age and further parameters on disease specific mortality was evaluated by multivariate Cox proportional hazards regression analyses. Results: Results showed that 8-year cancer-specific survival was $79.6 \%$ in those aged $\leq 49$ years, $70.6 \%$ in those aged $50-64$ years, $65.3 \%$ in those aged $65-74$ years, and $56.0 \%$ in those aged 75-84 years. These differences were significant as judged by a univariate log-rank test $(P<0.001)$ and multivariate Cox regression $(P<0.001)$. Age-based survival improvement was most obvious in patients diagnosed from 2005 to 2009 and with the following clinicopathologic characteristics: female, white race, low pathological grade, and localized stage. There was no obvious disparity of age-based survival improvement with regard to marital status or histologic type. No age-based survival improvement was observed in patients of the black race, pathological grade IV, or distant stage ( $P=0.05, P=0.07$, and $P=0.07$, respectively).

Conclusion: These data suggest that age is an independent prognostic factor for survival in patients with kidney cancer and that age-based survival improvement is associated with particular clinicopathologic characteristics.

Keywords: renal tumor, age groups, prognosis, epidemiology, SEER

\section{Introduction}

An estimated 65,340 Americans will be diagnosed with kidney cancer and 14,970 will die of the disease in the USA in $2018 .{ }^{1}$ Approximately $90 \%$ of renal tumors are renal cell carcinoma (RCC), and approximately $80 \%$ of these are clear cell carcinoma. ${ }^{2,3}$ RCC comprises approximately $3.8 \%$ of all new cancers, with a median age at diagnosis of 64 years. Younger age at diagnosis has been demonstrated to be a significant prognostic factor for cancer-specific survival (CSS) in numerous malignancies. ${ }^{4-10}$ With respect to kidney cancer, previous studies reported that younger patients had a favorable histological subtype and pathological features with better survival than older patients, ${ }^{11-16}$ although no difference in prognosis between young and old patients with RCC has been reported. ${ }^{17-21}$ Some of these studies included only patients in restricted age groups or were limited by sample size or follow-up periods. Thus, until now, the role of age as a prognostic factor in patients with RCC is still controversial. Furthermore, the association of age-based 
survival with regard to clinicopathologic characteristics is unclear. We designed our study to specifically evaluate the CSS of four subgroups of patients, based on age at diagnosis, by analyzing the Surveillance, Epidemiology, and End Results (SEER)-registered database. The degree of age-based survival improvement by sex, race, marital status, year of diagnosis, pathological grade, histological type, and stage was measured.

\section{Methods}

\section{Patient selection in the SEER database}

The SEER, a population-based reporting system, was surveyed for retrospective collection of data used in this analysis. We analyzed data from 18 population-based cancer registries included in the SEER program of the National Cancer Institute. The SEER data are publicly available for studies of cancer-based epidemiology and survival analysis. Because no personal identifying information was used in the analysis and since there was no interaction with human subjects, this study was granted an exemption from ethics approval from the Institutional Review Board of the Lihuili Hospital, Ningbo Medical Center on March 30, 2012.

Cases of kidney carcinoma (C64.9) diagnosed from 1990 to 2009 were extracted from the SEER database (SEER * Stat 8.3.4) according to Site Recode classifications. Only patients between 12 and 84 years of age, with a single primary kidney tumor, were included in the study. The age range was based on adequate study and follow-up time periods. Demographic variables including the year of diagnosis, age at diagnosis, sex, race, marital status, and tumor characteristics (histologic type, pathological grade, and SEER historic stage) were obtained from the registry databases. Patients with unknown survival months or SEER historic stage were excluded.

This study was based on the publicly available data from the SEER database with permission granted to access these research data (SEER*stat username: liuk).

\section{Statistical analysis}

CSS was calculated from the date of diagnosis to the date of cancer-specific death. Deaths attributed to kidney cancer were treated as events and deaths from other causes were treated as censored observations. The intergroup comparison of clinicopathologic variables were performed with the chisquared test. Survival was analyzed using the Kaplan-Meier method. ${ }^{22}$ The association between each of the potential prognostic factors and the estimated CSS was tested with the log-rank test. ${ }^{23}$ Multivariate analysis was performed using the Cox regression model. ${ }^{24} \mathrm{HRs}$ and $95 \%$ confidence intervals for cancer-specific death associated with age were calculated using Cox proportional hazards models for patients diagnosed during the time periods 1995-1999, 2000-2004, and 2005-2009, which were compared to those diagnosed at baseline, 1990-1994. Cox proportional hazards models were also used to calculate trend tests to calculate $P$-values for improvements in cancer survival. All models were adjusted for sex, race (white, black, or other), marital status at diagnosis (married, ever married, or never married), histologic type (clear cell carcinoma or non-clear cell carcinoma), pathological grade (grade I, II, III, or IV), SEER historic stages (localized, regional, and distant), age (20-49, 50-64, 65-74, or 75-84 years) and year at diagnosis (1990-1994, 1995-1999, 2000-2004, or 2005-2009). "Percentage by age" was calculated as the number of patients diagnosed at a certain age divided by the total number of kidney cancer patients in the database. GaussAmp nonlinear fitting (normal distribution fitting) was performed using the following formula (Equation 1):

$$
y=y_{0} A^{-\frac{\left(x-x_{C}\right)^{2}}{2 w^{2}}}
$$

The GaussAmp fitted curves for different diagnosis periods were plotted using one coordinated system to enable simple visualization and intuitive distribution comparisons. The area under each fitted curve was painted a different color. The statistical test was two-sided and $P<0.05$ was considered statistically significant. PASW Statistics 19 (SPSS Inc., Chicago, IL, USA) was used for the statistical analysis. Figure plotting and GaussAmp fitting were performed using Origin Pro version 2017 (OriginLab Corporation, Northampton, MA, USA).

\section{Results}

\section{Patient characteristics}

This study included 97,875 patients in the SEER database from 1990 to 2009 who met the inclusion criteria. There were 18,615 patients $12-49$ years of age, 38,391 patients 50-64 years of age, 25,064 patients 65-74 years of age, and 15,805 patients 75-84 years of age. There were 61,662 (63\%) males and 36,213 (37\%) females. The median diagnosis age was 62 years (range, 12-84) and the majority of the patients were white $(71.1 \%)$. Patient demographics and pathological features based on different age groups are summarized in Table 1.

\section{Impact of age on CSS time in patients with kidney cancer}

The distribution of age at diagnosis for kidney cancer changed over the 20 -year study period. The percentage of patients aged 
Table I Patient characteristics

\begin{tabular}{|c|c|c|c|c|c|c|}
\hline \multirow[t]{2}{*}{ Variable } & \multirow{2}{*}{$\begin{array}{l}\text { Total } \\
\mathrm{n}=97,875\end{array}$} & \multicolumn{4}{|l|}{ Age (years) } & \multirow[t]{2}{*}{$P$-value } \\
\hline & & $\begin{array}{l}12-49 \\
n=|8,6| 5(\%)\end{array}$ & $\begin{array}{l}50-64 \\
n=38,391(\%)\end{array}$ & $\begin{array}{l}65-74 \\
n=25,064(\%)\end{array}$ & $\begin{array}{l}75-84 \\
n=I 5,805(\%)\end{array}$ & \\
\hline \multicolumn{7}{|l|}{$\overline{\text { Sex }}$} \\
\hline Male & 61,662 & II,773 (63.2) & $25,695(66.9)$ & I5,488 (6I.8) & $8,706(55.1)$ & $<0.001$ \\
\hline Female & 36,213 & $6,842(36.8)$ & $12,696(33.1)$ & $9,576(38.2)$ & $7,099(44.9)$ & \\
\hline \multicolumn{7}{|l|}{ Race } \\
\hline White & 81,181 & $14,725(79.1)$ & $31,584(82.3)$ & $21,170(84.5)$ & $13,702(86.7)$ & $<0.001$ \\
\hline Black & $10,69 \mid$ & $2,579(13.9)$ & 4,490 (II.7) & $2,404(9.6)$ & I,218 (7.7) & \\
\hline Other & 6,003 & I,3 I I (7.0) & $2,317(6.0)$ & I,490 (5.9) & $885(5.6)$ & \\
\hline \multicolumn{7}{|c|}{ Pathological grading } \\
\hline Grade I & 10,500 & $2,445(13.1)$ & $4,150(10.8)$ & $2,489(9.9)$ & $1,416(8.9)$ & $<0.001$ \\
\hline Grade II & 32,024 & $6,732(36.2)$ & $13,056(34.0)$ & $7,900(31.5)$ & $4,336(27.4)$ & \\
\hline Grade III & 17,660 & $3,242(17.4)$ & $7,338(19.1)$ & $4,589(18.3)$ & $2,491(15.8)$ & \\
\hline Grade IV & 4,945 & $890(4.8)$ & $2, I 12(5.5)$ & $\mathrm{I}, 268(5.1)$ & $675(4.3)$ & \\
\hline Unknown & 32,746 & $5,306(28.5)$ & II,735 (30.6) & $8,818(35.2)$ & $6,887(43.6)$ & \\
\hline \multicolumn{7}{|c|}{ Marital status at diagnosis } \\
\hline Married & 62,047 & II,I95 (60.I) & $25,8 \mid 4(67.2)$ & $16,442(65.6)$ & $8,596(54.4)$ & $<0.001$ \\
\hline Ever married $^{\mathrm{a}}$ & 19,584 & 2047 (I I.0) & $6,152(16.1)$ & $5,729(22.9)$ & $5,656(35.8)$ & \\
\hline Never married & 16,244 & $5,373(28.9)$ & $6,425(16.7)$ & 2,893 (II.5) & I,553 (9.8) & \\
\hline \multicolumn{7}{|l|}{ Stage } \\
\hline Localized & 62,668 & $13,7 \mid 3(73.6)$ & $24,744(64.4)$ & $15,134(60.4)$ & $9,077(57.4)$ & $<0.001$ \\
\hline Regional & $|6,73|$ & $2,45 \mid(13.2)$ & $6,434(16.8)$ & 4,847 (19.3) & $2,999(19.0)$ & \\
\hline Distant & 18,476 & $2,45 \mathrm{I}(13.2)$ & $7,213(18.8)$ & $5,083(20.3)$ & $3,729(23.6)$ & \\
\hline \multicolumn{7}{|l|}{ Year of diagnosis } \\
\hline 1990-1994 & 9,355 & I,623 (8.7) & $3,369(8.8)$ & 2,782 (I I.I) & I,58I (I0.0) & $<0.001$ \\
\hline $1995-1999$ & 12,016 & $2,301(12.4)$ & 4,309 (II.2) & $3,336(13.3)$ & $2070(13.1)$ & \\
\hline 2000-2004 & 33,573 & $6,437(34.6)$ & 12,995 (33.9) & $8,479(33.8)$ & $5,662(35.8)$ & \\
\hline 2005-2009 & 42,931 & $8,254(44.3)$ & $17,718(46.1)$ & $10,467(41.8)$ & $6,492(4 I .1)$ & \\
\hline \multicolumn{7}{|l|}{ Histologic type } \\
\hline CCR & 78,803 & $14,9 \mid 6(80.1)$ & $31,222(81.3)$ & 20,281 (80.9) & I2,384 (78.4) & $<0.001$ \\
\hline $\mathrm{N}-\mathrm{CCR}$ & 19,072 & 3,699 (19.9) & $7,169(18.7)$ & 4,783 (19.1) & 3,421 (2I.6) & \\
\hline
\end{tabular}

Note: ancluding divorced, widowed, and separated.

Abbreviations: CCR, clear cell carcinoma; N-CCR, non-clear cell carcinoma.

12-49 years slightly increased, with the most demonstrable change in patients aged 50-64 years. In contrast, the percentage of patients aged 65-74 years decreased over time. The percentage of patients aged 75-84 years remained relatively stable over the 20 -year period (Figure 1). Moreover, as judged by the distribution of patients by age at diagnosis using a GaussAmp fitting curve, a tendency for younger-age kidney cancer morbidity was observed (Figure 2). The 8-year CSS was $79.6 \%$ for those aged $12-49$ years, $70.6 \%$ for $50-64$ years, $65.3 \%$ for $65-74$ years, and $56.0 \%$ for $75-84$ years, which was significant as judged by the univariate log-rank test $(P<0.001$; Figure 3$)$. As judged by univariate analysis, significant risk factors for poor survival (all $P<0.001$ ) involved the following categories: male, higher tumor grade, ever married at diagnosis, distant stage, earlier year of diagnosis, and nonclear cell carcinoma (Table 2). When multivariate analysis with Cox regression was performed, these risk factors were convinced as independent prognostic factors (Table 2).

\section{Disparity in age-based survival improvement for kidney cancer patients with various clinicopathologic features}

All age groups showed improved kidney cancer survival from 1990 to 2009 with the survival improvement greater for younger aged groups (Figure 4). For patients aged 12-49 years, the adjusted HR $(95 \% \mathrm{CI})$ for those diagnosed from 2005 to 2009 was 0.39 (95\% CI, 0.44-0.54) when compared with patients diagnosed from 1990 to 1994 . However, for elderly patients aged 75-84 years, the corresponding HR (95\% CI) diagnosed from 2005 to 2009 was only 0.73 (95\% CI, 0.67-0.79) compared with the patients diagnosed from 1990 to 1994. Moreover, we evaluated the age-based survival improvement for kidney cancer with various clinicopathologic characteristics (Figures 5 and 6). Improvement in survival of the younger aged groups was most obvious in patients diagnosed during 2005-2009 with an adjusted HR of 2.92 (95\% CI, 2.72-3.13). For those aged $70-84$ years, 
45

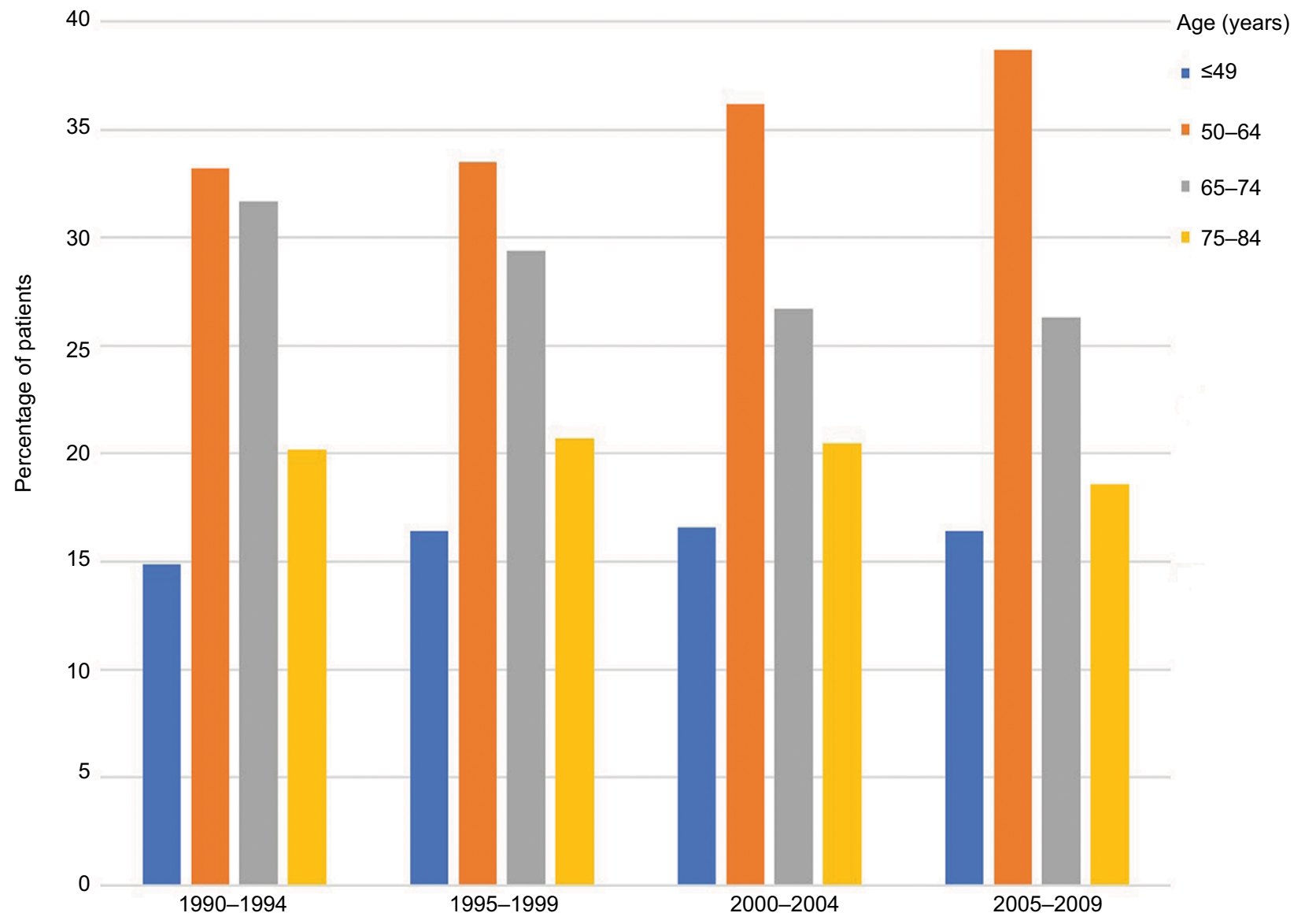

Figure I The distribution of the age at kidney cancer diagnosis from 1990 to 2009.

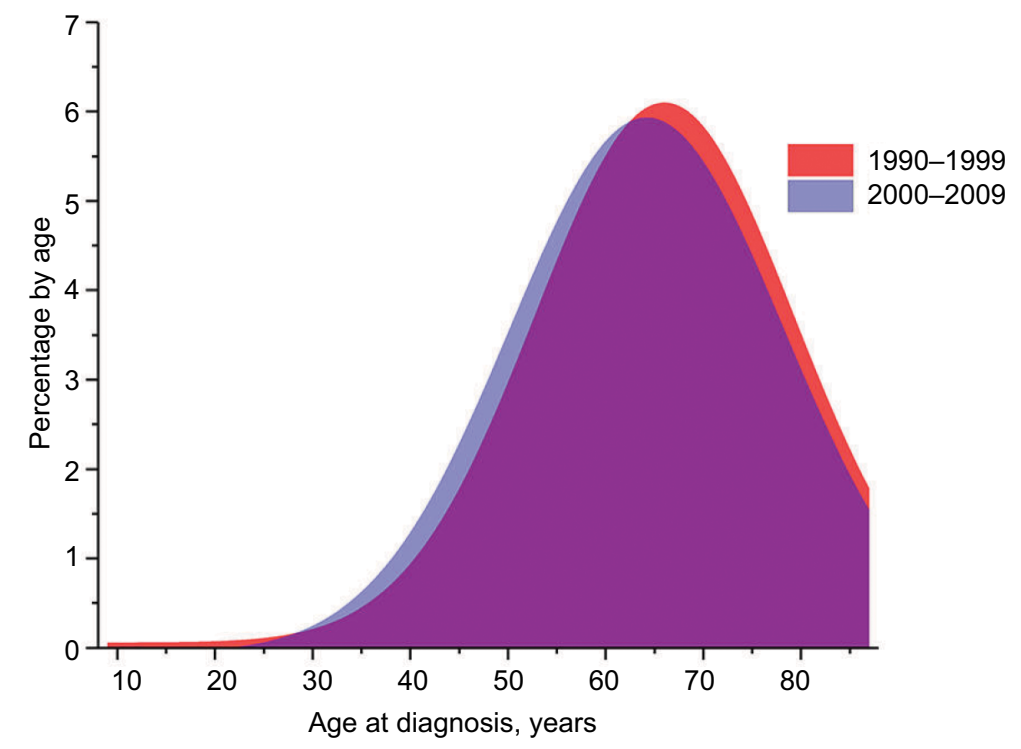

Figure 2 The distribution of patients by age at diagnosis using a GaussAmp fitting curve according to different periods of diagnosis. 


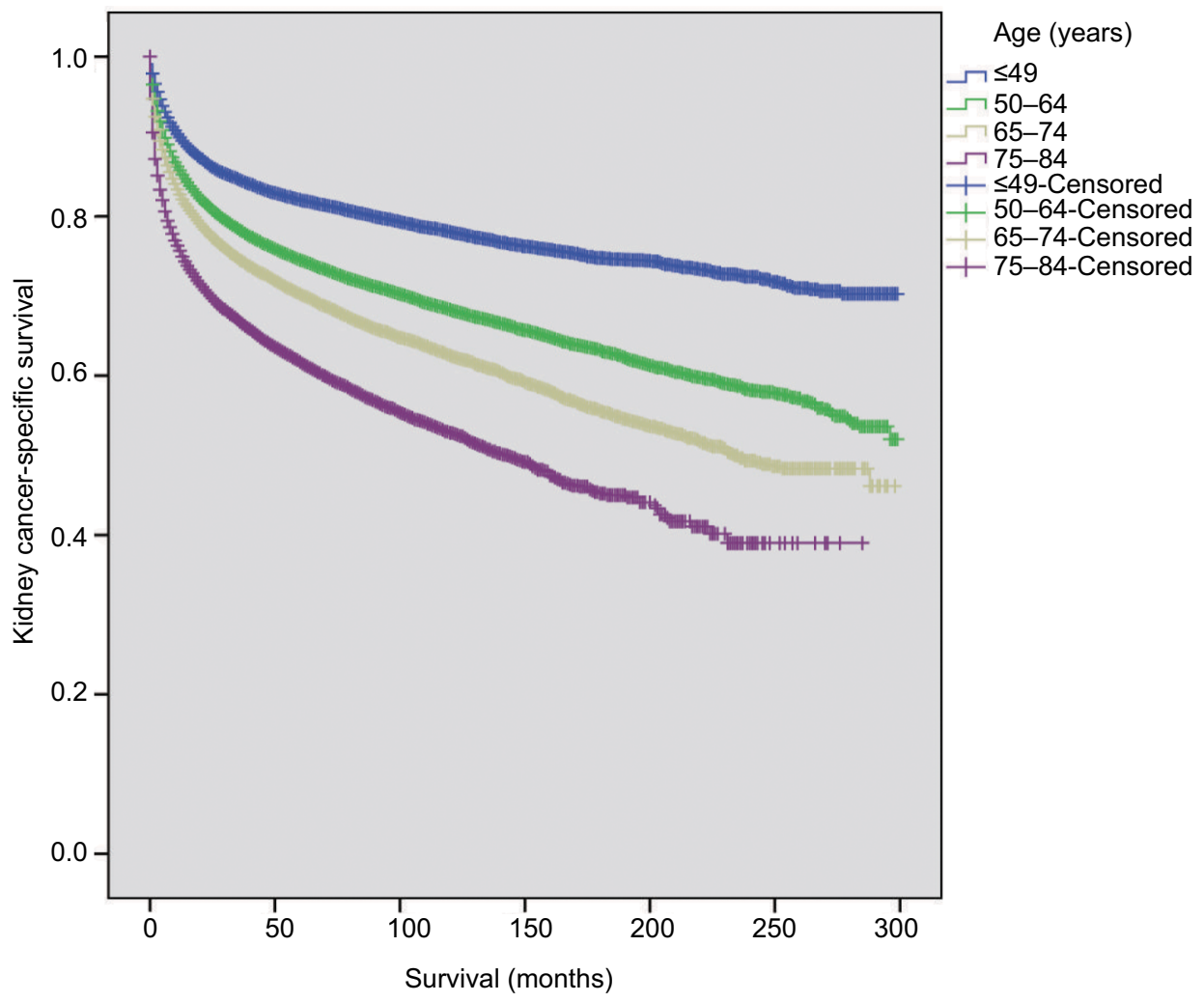

Figure 3 Survival curves in patients with kidney cancer according to different age subgroups.

when compared to those aged $12-49$ years, the adjusted HR was 2.14 (95\% CI, 1.92-2.39) for the same age groups from 1990 to 1994 . There was a statistically significant age-based survival improvement based on histologic type, sex, and marital status. No apparent difference in age-based survival improvement was observed between clear cell and non-clear cell carcinomas. Female kidney cancer patients experienced greater age-based survival improvements than males with an obvious difference in those survival improvements based on marital status. Furthermore, significant survival improvements were observed for race, pathological grade, and stage with the exception of black race, grade IV, and distant stage ( $P=0.05, P=0.07$, and $P=0.07$, respectively). White and African-American cancer patients experienced similar degrees of age-based improvements in survival, but patients with pathological grade I and localized stage showed the greatest survival improvement.

\section{Discussion}

To our knowledge, this is the first large population-based study to evaluate the prognostic impact of age at diagnosis and the importance of clinicopathologic characteristics for kidney cancer survival using the SEER-registered database.
The conventional peak for RCC onset is in the seventh decade of life with only $3 \%-5 \%$ of RCC diagnoses in patients $<40$ years of age. ${ }^{25}$ Previous studies have shown that the mean age for diagnosis of kidney cancer has decreased from 64.7 to 62.7 years with the proportion of patients diagnosed before age 65 increased from $45.9 \%$ to $55.3 \%$ during the period from 1975 to $2006 .{ }^{26}$ Furthermore, overall renal cancer diagnosis in the youngest age group (20-39 years) increased more quickly than all other age groups. In this study, the median age at diagnosis was 62 years with a tendency for younger cancer morbidity.

Analysis of the SEER database indicates that the 5-year survival for localized cancer has increased from $88.4 \%$ (1992-1995) to $92.6 \%$ with advanced disease increasing from $7.3 \%$ to $11.7 \%$ (2007-2013). ${ }^{27}$ Pengxiang Li et al found that RCC patients diagnosed from 2006 to 2010 showed improved survival compared with those diagnosed from 2000 to $2005 .^{28}$ Similar to those results, this study found that all age groups showed improved kidney cancer survival from 1990 to 2009. It is worth noting that survival improvement was greatest for younger age groups than for elderly patients. Improvements in survival are attributed to improved cancer screening, as well as advances in cancer treatments (surgery, radiotherapy, 
Table 2 Univariate and multivariate survival analyses of patients with kidney cancer according to various clinicopathological variables

\begin{tabular}{|c|c|c|c|c|}
\hline Variable & $\mathbf{N}$ & 8-year CSS (\%) & $\begin{array}{l}\text { Univariate } \\
P \text {-value }\end{array}$ & $\begin{array}{l}\text { Multivariate } \\
P \text {-value }\end{array}$ \\
\hline \multicolumn{5}{|l|}{$\overline{\text { Sex }}$} \\
\hline Male & 61,662 & 67.3 & $<0.001$ & $<0.001$ \\
\hline Female & 36,213 & 74.1 & & \\
\hline \multicolumn{5}{|l|}{ Race } \\
\hline White & 81,181 & 68.8 & 0.189 & $<0.001$ \\
\hline Black & $|0,69|$ & 68.9 & & \\
\hline Other & 6,003 & 70 & & \\
\hline \multicolumn{5}{|c|}{ Pathological grade } \\
\hline Grade I & 10,500 & 89.9 & $<0.001$ & $<0.001$ \\
\hline Grade II & 32,024 & 85.3 & & \\
\hline Grade III & 17,660 & 61.8 & & \\
\hline Grade IV & 4,945 & 34.7 & & \\
\hline Unknown & 32,746 & 54.4 & & \\
\hline \multicolumn{5}{|c|}{ Marital status at diagnosis } \\
\hline Married & 62,047 & 70.3 & $<0.001$ & $<0.001$ \\
\hline Ever married ${ }^{\mathrm{a}}$ & 19,584 & 62.8 & & \\
\hline Never married & 16,244 & 70.2 & & \\
\hline \multicolumn{5}{|l|}{ Stage } \\
\hline Localized & 62,668 & 89.4 & $<0.001$ & $<0.001$ \\
\hline Regional & $|6,73|$ & 57.7 & & \\
\hline Distant & 18,476 & 6.8 & & \\
\hline \multicolumn{5}{|l|}{ Year of diagnosis } \\
\hline $1990-1994$ & 9,355 & 59.7 & $<0.001$ & $<0.001$ \\
\hline $1995-1999$ & 12,016 & 64.1 & & \\
\hline 2000-2004 & 33,573 & 67.5 & & \\
\hline $2005-2009$ & 42,931 & 74.1 & & \\
\hline \multicolumn{5}{|l|}{ Age (years) } \\
\hline $12-49$ & 18,615 & 79.6 & $<0.001$ & $<0.001$ \\
\hline $50-64$ & 38,391 & 70.6 & & \\
\hline $65-74$ & 25,064 & 65.3 & & \\
\hline $75-84$ & 15,805 & 56 & & \\
\hline \multicolumn{5}{|l|}{ Histologic type } \\
\hline CCR & 78,803 & 69.5 & $<0.001$ & $<0.001$ \\
\hline $\mathrm{N}-\mathrm{CCR}$ & 19,072 & 66.1 & & \\
\hline
\end{tabular}

Note: ancluding divorced, widowed, and separated.

Abbreviations: CSS, cancer-specific survival; CCR, clear cell carcinoma; N-CCR, non-clear cell carcinoma.

chemotherapy, and targeted therapies). Before 2006, systemic treatment of advanced RCC was limited to cytokines, eg interferon-alfa and interleukin-2. From December 2005 to October 2009, six targeted agents (four that targeted angiogenesis and two rapamycin [mTOR]-targeted therapies) were approved for the treatment of advanced RCC by the US Food and Drug Administration. These targeted drug therapies significantly extended survival time for kidney cancer patients. ${ }^{29-31}$

Like most malignancies, the most important prognostic factors at diagnosis for kidney cancer survival are tumor stage, pathological grade, local extent of tumor, regional lymph node involvement, and evidence of metastatic disease. Patient age at diagnosis of kidney cancer has been investigated with inconsistent results. Most investigations have found that younger patients present with a lower tumor stage and with a higher likelihood for nephron sparing surgery than older patients. A few investigations have compared kidney cancer survival rates by sex, actual age, and age at diagnosis, but the importance of age-based survival improvement based on clinicopathologic characteristics is unclear. Muyan Cai et al found that increasing age was associated with a higher incidence of cancer-specific mortality and an age cutoff of 45 years independently predicted CSS of patients with localized RCC. ${ }^{32}$ Jung et al reported that young age was an independent prognostic factor for CSS only in low-stage clear cell RCC but not in high-stage clear cell RCC. ${ }^{16}$ In agreement with these findings, this study showed a significant age-based survival improvement only in localized stage disease, but 


\begin{tabular}{|c|c|c|c|}
\hline \multicolumn{3}{|c|}{ Age (years) } & $\mathrm{HR}(95 \% \mathrm{Cl})$ \\
\hline \multirow[t]{4}{*}{$\leq 49$} & 1990-1994 & & 1 [Reference] \\
\hline & 1995-1999 & $\leftarrow$ & $0.84(0.75-0.94)$ \\
\hline & 2000-2004 & + & $0.70(0.64-0.77)$ \\
\hline & 2005-2009 & $\leftarrow$ & $0.49(0.44-0.54)$ \\
\hline \multirow[t]{4}{*}{$50-64$} & 1990-1994 & & 1 [Reference] \\
\hline & 1995-1999 & & $0.96(0.89-1.02)$ \\
\hline & 2000-2004 & $\bullet$ & $0.76(0.72-0.81)$ \\
\hline & 2005-2009 & - & $0.56(0.53-0.60)$ \\
\hline \multirow[t]{4}{*}{$65-74$} & 1990-1994 & & 1 [Reference] \\
\hline & 1995-1999 & + & $0.92(0.85-0.99)$ \\
\hline & 2000-2004 & $\bullet$ & $0.76(0.72-0.82)$ \\
\hline & 2005-2009 & - & $0.58(0.54-0.62)$ \\
\hline \multirow[t]{4}{*}{$75-84$} & 1990-1994 & & 1 [Reference] \\
\hline & 1995-1999 & & $1.04(0.94-1.14)$ \\
\hline & 2000-2004 & $\rightarrow$ & $0.86(0.79-0.94)$ \\
\hline & 2005-2009 & 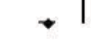 & $0.73(0.67-0.79)$ \\
\hline
\end{tabular}

Figure 4 Multivariate-adjusted HRs and $95 \%$ Cls for cancer-specific death associated with year of diagnosis according to age. not in regional or distant stage disease. Sangchul Lee et al found that Korean women with RCC had a lower proportion of clear cell but a higher proportion of chromophobe histology and that this histological difference accounted for the better survival rates for Korean women than men. ${ }^{33}$ Edward N. Rampersaud et al reported survival advantage for women $<42$ years and $42-58$ years of age, with no advantage for women $\geq 59$ years of age. ${ }^{34}$ Age was an independent predictor of disease-specific survival in women, but not in men. After examination of the EUROCARE-4 database, Micheli et al found that a highly significant age-adjusted advantage was observed in women overall, with greater relative survival noted in younger age groups. ${ }^{35}$ Interestingly, women suffered a survival disadvantage in comparison to men in the oldest age group (75-99 years of age). These results are similar to this study in that being female was a significant risk factor for survival. However, female patients showed a greater age-based survival improvement than male patients.

\section{A}

\begin{tabular}{|c|c|c|c|}
\hline Year & Age (years) & & $\mathrm{HR}(95 \% \mathrm{Cl})$ \\
\hline \multirow[t]{4}{*}{ 1990-1994 } & $\leq 49$ & & 1 [Reference] \\
\hline & $50-64$ & & $1.48(1.35-1.63)$ \\
\hline & $65-74$ & & $1.79(1.63-1.97)$ \\
\hline & $75-84$ & $\rightarrow$ & $2.14(1.92-2.39)$ \\
\hline \multirow[t]{3}{*}{ 1995-1999 } & $\leq 49$ & & 1 [Reference] \\
\hline & $\begin{array}{l}50-64 \\
65-74\end{array}$ & & $\begin{array}{l}1.65(1.51-1.80) \\
1.92(1.75-2.10)\end{array}$ \\
\hline & $75-84$ & $\bullet$ & $2.57(2.33-2.84)$ \\
\hline \multirow[t]{4}{*}{ 2000-2004 } & $\leq 49$ & & 1 [Reference] \\
\hline & $50-64$ & & $1.53(1.44-1.62)$ \\
\hline & $65-74$ & & $1.85(1.74-1.97)$ \\
\hline & $75-84$ & - & $2.51(2.36-2.68)$ \\
\hline \multirow[t]{5}{*}{ 2005-2009 } & $\leq 49$ & & 1 [Reference] \\
\hline & $50-64$ & & $1.59(1.49-1.69)$ \\
\hline & $65-74$ & & $1.93(1.80-2.07)$ \\
\hline & $75-84$ & $\rightarrow$ & $2.92(2.72-3.13)$ \\
\hline & 0.00 & $2.00 \quad 4.00$ & \\
\hline
\end{tabular}

\begin{tabular}{|c|c|c|c|}
\hline Histological type & Age (years) & & $\mathrm{HR}(95 \% \mathrm{Cl})$ \\
\hline \multirow[t]{4}{*}{ CCR } & $\leq 49$ & - & 1 [Reference] \\
\hline & $50-64$ & - & $1.63(1.56-1.70)$ \\
\hline & $65-74$ & • & $2.01(1.92-2.09)$ \\
\hline & $75-84$ & & $2.70(2.58-2.83)$ \\
\hline \multirow[t]{5}{*}{$\mathrm{N}-\mathrm{CCR}$} & $\leq 49$ & • & 1 [Reference] \\
\hline & $50-64$ & & $1.27(1.18-1.38)$ \\
\hline & $65-74$ & $\rightarrow$ & $1.57(1.45-1.71)$ \\
\hline & $75-84$ & & $2.33(2.14-2.52)$ \\
\hline & 0.00 & 2.00 & 4.00 \\
\hline
\end{tabular}

B

$\begin{array}{ll}\text { Grade } & \text { Age (years) } \\ \text { Grade I } & \leq 49 \\ & 50-64 \\ & 65-74 \\ & 75-84 \\ \text { Grade II } & \leq 49 \\ & 50-64 \\ & 65-74 \\ & 75-84 \\ \text { Grade III } & \leq 49 \\ & 50-64 \\ & 65-74 \\ & 75-84 \\ \text { Grade IV } & \leq 49 \\ & 50-64 \\ 65-74 \\ 75-84\end{array}$

$\operatorname{HR}(95 \% \mathrm{Cl})$

1 [Reference]

$1.90(1.58-2.28)$

$2.91(2.40-3.52)$

$4.75(3.89-5.81)$

1 [Reference]

$1.78(1.63-1.95)$

$2.38(2.16-2.16)$

$3.25(2.93-3.60)$

1 [Reference]

$1.16(1.08-1.25)$

$1.36(1.26-1.47)$

$1.66(1.52-1.80)$

1 [Reference]

$1.09(0.99-1.21)$

$1.13(1.01-1.26)$

$1.27(1.12-1.44)$

D

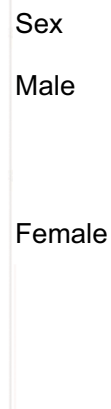

$\operatorname{HR}(95 \% \mathrm{Cl})$

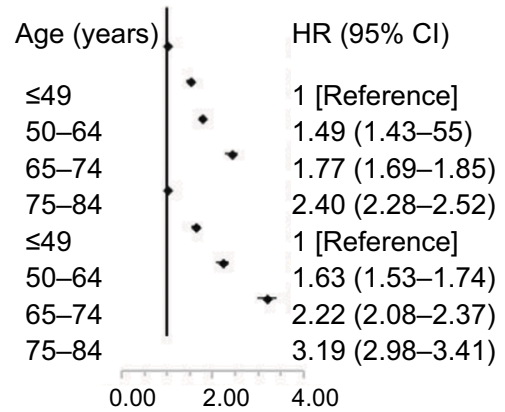

Figure 5 Multivariate-adjusted HRs and $95 \%$ Cls for cancer-specific death associated with age according to year of diagnosis (A), pathological grade (B), histological type (C), and sex (D).

Abbreviations: CCR, clear cell carcinoma; N-CCR, non-clear cell carcinoma. 
A

B

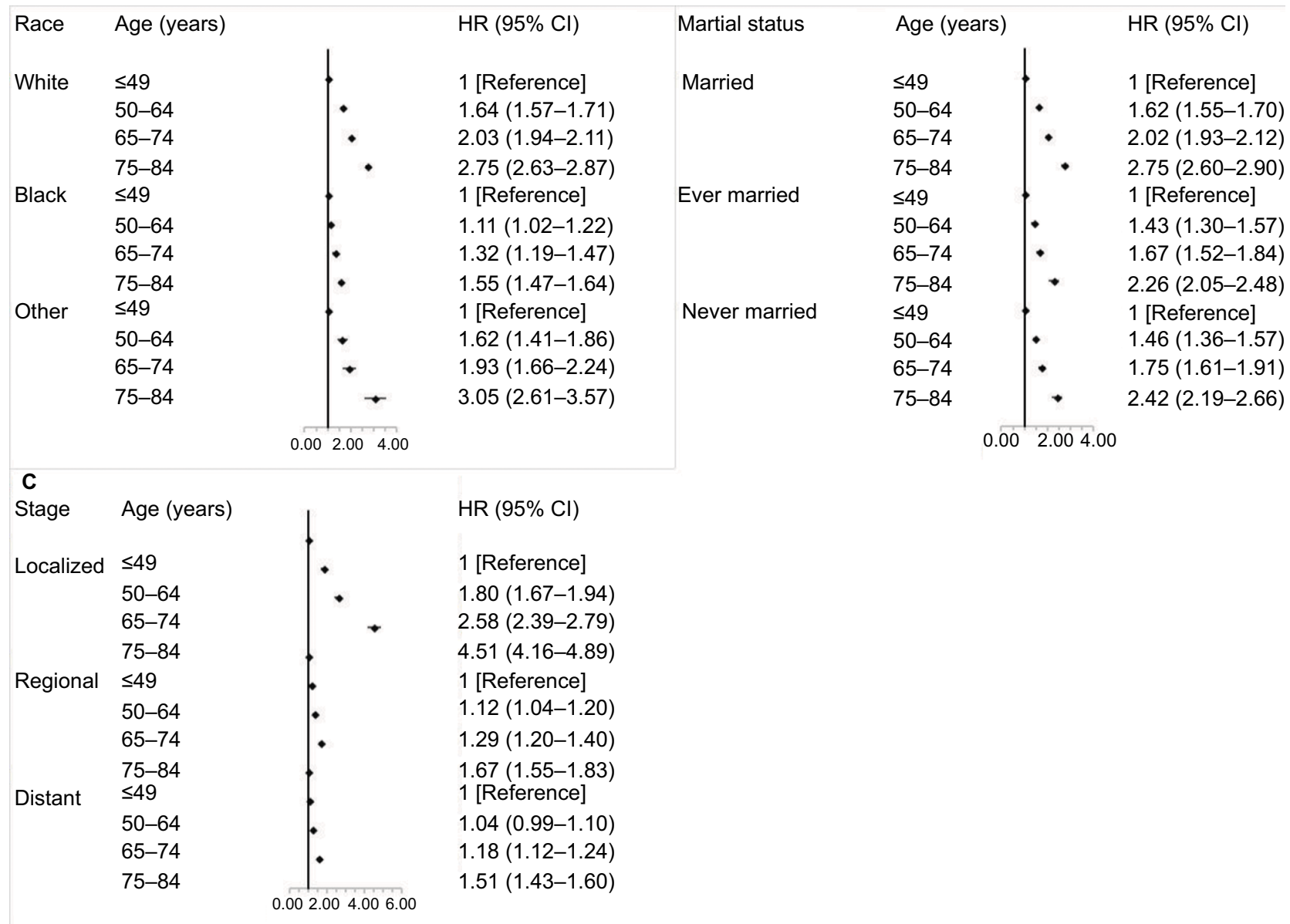

Figure 6 Multivariate-adjusted HRs and $95 \%$ Cls for cancer-specific death associated with age according to race (A), marital status at diagnosis (B), and stage (C).

These findings suggest that there is a biologic, rather than a cultural basis for the survival advantage of women prior to menopause. The effect of hormones on the development and progression of RCC requires further investigation. A previous study demonstrated a greater degree of RCC-specific survival with regard to nephrectomy status, age, and gender in the later years of the post-targeted period (2006-2010) than the period $2000-2005 .{ }^{28}$ Similar to these results, this study also showed that age-based survival improvement was more apparent from 2005 to 2009, indicating that younger patients with kidney cancer may benefit more than elderly patients from advances in cancer treatment, including surgery, radiotherapy, chemotherapy, and targeted therapies. Another noteworthy aspect of this study was that no age-based survival improvement was observed specifically in those of the black race or those with pathological grade IV. Studies have shown that white people consistently have a survival advantage over black people, regardless of tumor characteristics or surgical treatment. ${ }^{36,37}$ But the underlying cause for this disparity is unknown and requires further investigation.

\section{The limitations in the study}

Although this is a large population-based study, it has several potential limitations. First, the SEER registry does not collect information on the comorbidities, nutritional status, or performance status of the patients. For example, elderly patients may undergo less aggressive treatment due to comorbidities and poor performance status. Moreover, data on individual socioeconomic status, lifestyle factors, and insurance coverage were not available, which may serve as potential confounding factors. Furthermore, the limitation of not having differentiated by $\mathrm{T}$ categories or Fuhrman degrees is explicit. Second, analysis of a nonrandomized patient population may introduce selection bias. Finally, the population was sampled over urban and foreign-born populations, which may affect the generalizability of the 
findings to the general US population. However, the power of this study is its strength.

\section{Conclusion}

Age is an independent prognostic factor for survival in patients with kidney cancer. Further, clinicopathologic characteristics associated with age-based survival should be considered crucial determinants in the treatment of kidney cancer.

\section{Acknowledgments}

The authors acknowledge the efforts of the SEER Program tumor registries in the creation of the SEER database. The interpretation and reporting of these data are the sole responsibility of the authors.

This work was supported by a grant from the Natural Science Foundation of Ningbo (number 2017A610193).

\section{Disclosure}

The authors report no conflicts of interest in this work.

\section{References}

1. Siegel RL, Miller KD, Jemal A. Cancer statistics, 2018. CA Cancer J Clin. 2018;68(1):7-30.

2. Moch H, Gasser T, Amin MB, Torhorst J, Sauter G, Mihatsch MJ. Prognostic utility of the recently recommended histologic classification and revised TNM staging system of renal cell carcinoma: a Swiss experience with 588 tumors. Cancer. 2000;89(3):604-614.

3. Leibovich BC, Lohse CM, Crispen PL, et al. Histological subtype is an independent predictor of outcome for patients with renal cell carcinoma. J Urol. 2010;183(4):1309-1316.

4. Chung M, Chang HR, Bland KI, Wanebo HJ. Younger women with breast carcinoma have a poorer prognosis than older women. Cancer. 1996;77(1):97-103.

5. Haymart MR. Understanding the relationship between age and thyroid cancer. Oncologist. 2009;14(3):216-221.

6. Voutilainen PE, Multanen MM, Leppäniemi AK, Haglund CH, Haapiainen RK, Franssila KO. Prognosis after lymph node recurrence in papillary thyroid carcinoma depends on age. Thyroid. 2001;11(10):953-957.

7. Pectasides D, Fountzilas G, Aravantinos G, et al. Epithelial ovarian carcinoma in younger vs older women: is age an independent prognostic factor? The Hellenic Oncology Cooperative Group experience. Int $J$ Gynecol Cancer. 2007;17(5):1003-1010.

8. Li M, Li JY, Zhao AL, Gu J. Do young patients with colorectal cancer have a poorer prognosis than old patients? J Surg Res. 2011;167(2):231-236.

9. Han W, Kim SW, Park IA, et al. Young age: an independent risk factor for disease-free survival in women with operable breast cancer. $B M C$ Cancer. 2004;4:82.

10. Delaloye JF, Pampallona S, Coucke PA, de Grandi P. Younger age as a bad prognostic factor in patients with carcinoma of the cervix. Eur $J$ Obstet Gynecol Reprod Biol. 1996;64(2):201-205.

11. Aziz A, May M, Zigeuner R, et al. Do young patients with renal cell carcinoma feature a distinct outcome after surgery? A comparative analysis of patient age based on the multinational CORONA database. J Urol. 2014;191(2):310-315.

12. Sánchez-Ortiz RF, Rosser CJ, Madsen LT, Swanson DA, Wood CG. Young age is an independent prognostic factor for survival of sporadic renal cell carcinoma. J Urol. 2004;171(6 Pt 1):2160-2165.
13. Taccoen X, Valeri A, Descotes JL, et al. Renal cell carcinoma in adults 40 years old or less: young age is an independent prognostic factor for cancer-specific survival. Eur Urol. 2007;51(4):980-987.

14. Jeong IG, Yoo $\mathrm{CH}$, Song $\mathrm{K}$, et al. Age at diagnosis is an independent predictor of small renal cell carcinoma recurrence-free survival. JUrol. 2009;182(2):445-450.

15. Karakiewicz PI, Jeldres C, Suardi N, et al. Age at diagnosis is a determinant factor of renal cell carcinoma-specific survival in patients treated with nephrectomy. Can Urol Assoc J. 2008;2(6):610-617.

16. Jung EJ, Lee HJ, Kwak C, Ku JH, Moon KC. Young age is independent prognostic factor for cancer-specific survival of low-stage clear cell renal cell carcinoma. Urology. 2009;73(1):137-141.

17. Kang HW, Seo SP, Kim WT, et al. Impact of young age at diagnosis on survival in patients with surgically treated renal cell carcinoma: a multicenter study. J Korean Med Sci. 2016;31(12):1976-1982.

18. Thompson RH, Ordonez MA, Iasonos A, et al. Renal cell carcinoma in young and old patients-is there a difference? J Urol. 2008;180(4):1262-1266.

19. Lieber MM, Tomera FM, Taylor WF, Farrow GM. Renal adenocarcinoma in young adults: survival and variables affecting prognosis. $J$ Urol. 1981;125(2):164-168.

20. Abou El Fettouh HI, Cherullo EE, El-Jack M, Al Maslamani Y, Novick AC. Sporadic renal cell carcinoma in young adults: presentation, treatment, and outcome. Urology. 2002;60(5):806-810.

21. Goetzl MA, Desai M, Mansukhani M, et al. Natural history and clinical outcome of sporadic renal cortical tumors diagnosed in the young adult. Urology. 2004;63(1):41-45.

22. Kaplan EL, Meier P. Nonparametric estimation from incomplete observations. J Am Stat Assoc. 1958;53(282):457-481.

23. Mantel N. Evaluation of survival data and two new rank order statistics arising in its consideration. Cancer Chemother Rep. 1966;50(3): 163-170.

24. Gill RD. Multistate life-tables and regression models. Math Popul Stud. 1992;3(4):259-276.

25. National Comprehensive Cancer Network (NCCN). NCCN Kidney Cancer Guidelines; 2018. Available from: https://www.nccn.org/professionals/physician_gls/pdf/kidney.pdf. Accessed February 2, 2018.

26. Nepple KG, Yang L, Grubb RL, Strope SA. Population based analysis of the increasing incidence of kidney cancer in the United States: evaluation of age specific trends from 1975 to 2006. J Urol. 2012;187(1):32-38.

27. Howlader N, Noone AM, Krapcho M. SEER Cancer Statistics Review, 1975-2014. Bethesda, MD: National Cancer Institute; 2017. Available from: https://seer.cancer.gov/csr/1975_2014/.Accessed September 21, 2017.

28. Li P, Wong YN, Armstrong K, et al. Survival among patients with advanced renal cell carcinoma in the pretargeted versus targeted therapy eras. Cancer Med. 2016;5(2):169-181.

29. Motzer RJ, Hutson TE, Tomczak P, et al. Sunitinib versus interferon alfa in metastatic renal-cell carcinoma. N Engl J Med. 2007;356(2):115-124.

30. Escudier B, Eisen T, Stadler WM, et al. Sorafenib in advanced clear-cell renal-cell carcinoma. $N$ Engl J Med. 2007;356(2):125-134.

31. Escudier B, Pluzanska A, Koralewski P, et al. Bevacizumab plus interferon alfa-2a for treatment of metastatic renal cell carcinoma: a randomised, double-blind phase III trial. Lancet. 2007;370(9605):2103-2111.

32. Cai M, Wei J, Zhang Z, et al. Impact of age on the cancer-specific survival of patients with localized renal cell carcinoma: martingale residual and competing risks analysis. PLoS One. 2012;7(10):e48489.

33. Lee S, Jeon HG, Kwak C, et al. Gender-specific clinicopathological features and survival in patients with renal cell carcinoma (RCC). BJU Int. 2012;110(2 Pt 2):E28-E33.

34. Rampersaud EN, Klatte T, Bass G, et al. The effect of gender and age on kidney cancer survival: younger age is an independent prognostic factor in women with renal cell carcinoma. Urol Oncol. 2014;32(1):30.e9-e13.

35. Micheli A, Ciampichini R, Oberaigner W, et al. The advantage of women in cancer survival: an analysis of EUROCARE-4 data. Eur J Cancer. 2009;45(6):1017-1027. 
36. Chow WH, Shuch B, Linehan WM, Devesa SS. Racial disparity in renal cell carcinoma patient survival according to demographic and clinical characteristics. Cancer. 2013;119(2):388-394.
37. Vaishampayan UN, Do H, Hussain M, Schwartz K. Racial disparity in incidence patterns and outcome of kidney cancer. Urology. 2003;62(6):1012-1017.

\section{Publish your work in this journal}

Cancer Management and Research is an international, peer-reviewed open access journal focusing on cancer research and the optimal use of preventative and integrated treatment interventions to achieve improved outcomes, enhanced survival and quality of life for the cancer patient. The manuscript management system is completely online and includes a very quick and fair peer-review system, which is all easy to use. Visit http://www.dovepress.com/testimonials.php to read real quotes from published authors. 